Manuscript to be submitted to the Journal of Applied Thermal Engineering

\title{
Analysis of a high-temperature heat exchanger for an externally-fired micro gas
} turbine

\author{
Fabiola Baina $^{a, b, *, 1}$, Anders Malmquist ${ }^{a, 2}$, Lucio Alejo ${ }^{b, 1}$, Björn Palm $^{a, 3}$, Torsten H. Fransson ${ }^{a, 4}$

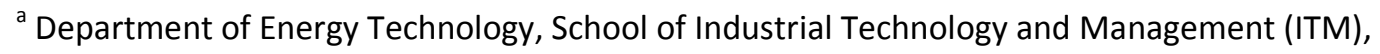 \\ Royal Institute of Technology (KTH), 10044 Stockholm Sweden \\ ${ }^{\mathrm{b}}$ Facultad de Ciencias y Tecnología (FCyT), Universidad Mayor de San Simón (UMSS), \\ Cochabamba, Bolivia \\ *Corresponding author at: Department of Energy Technology, School of Industrial Technology \\ and Management (ITM), Royal Institute of Technology (KTH), 10044 Stockholm Sweden. Tel.: \\ +46879074 42; fax: +468204161 \\ E-mail addresses: fabiola@kth.se (F. Baina), andmal@kth.se (A. Malmquist) \\ lalejo@fcyt.umss.edu.bo (L. Alejo), Bjorn.Palm@energy.kth.se (B. Palm) \\ torsten.fransson@energy.kth.se (T.H. Fransson). \\ ${ }^{1}$ Tel.: +5914 2336 48; fax: +5914232548. \\ ${ }^{2}$ Tel.: +468 79074 38; fax: +468204161. \\ ${ }^{3}$ Tel.: +468 79074 53; fax: +468204161. \\ ${ }^{4}$ Tel.: +468 79074 75; fax: +468204161.
}




\begin{abstract}
The externally-fired gas turbine (EFGT) can convert fuels such as coal, biomass, biomass gasification gas and solar energy into electricity and heat. The combination of this technology with biomass gasification gas represents an interesting option for gasification, for which it has been difficult to find a conversion technology. In this system, the heat exchanger deals with the contaminants of biomass derived gas instead of the turbine itself. However, these contaminants can build a deposit layer in the heat exchanger that can affect its performance. The heat exchanger is important in externally fired gas turbines since the turbine inlet temperature is directly dependent on its performance. Several studies on heat exchangers for externally fired gas turbines have been carried out. However, very few detailed studies were found comparing the performance of heat exchangers for externally fired gas turbines considering the effect of deposit materials on the surfaces. In this regard, this work compares the performance of a corrugated plate heat exchanger and a two-tube-passes shell and tube heat exchanger considering the effect of thickness of deposit material with different thermal conductivities on pressure drop and effectiveness. The results show that the effectiveness of the corrugated plate heat exchanger is more influenced at larger thicknesses of deposit materials than the two-tube-passes shell and tube heat exchanger. There is an exponential increase in the pressure drop of the plate heat exchanger while a monotonic increase of pressure drop is seen for the shell and tube heat exchanger. The increase in the thickness of the deposit material has two effects. On one hand, it increases the resistance to heat transfer and on the other hand, it reduces the through flow area increasing the velocity and hence the heat transfer coefficient. Additionally, the effectiveness of the heat exchangers had a stronger influence on the power output than the pressure drop.
\end{abstract}

Keywords: externally fired gas turbine, heat exchanger, biomass gasification gas, deposit materials, effectiveness, pressure drop 


\section{Nomenclature}

A: Heat transfer area, $m^{2}$

b: Plate distance, $\mathrm{mm}$

C: Heat capacity rate, $\mathrm{W} / \mathrm{K}$

$\mathrm{C}_{\mathrm{p}}$ : Heat capacity, $\mathrm{kJ} / \mathrm{kg}-\mathrm{K}$

$\mathrm{d}$ : diameter, $\mathrm{m}$

$\mathrm{d}_{\mathrm{e}}$ : equivalent diameter, $\mathrm{m}$

$d_{h}$ : Hydraulic diameter, $m$

Ds: Shell diameter, $\mathrm{m}$

De: equivalent diameter for the shell side, $m$

f: Friction factor, dimensionless

$h$ : Heat transfer coefficient, $W / m^{2} K$

$\mathrm{k}$ : Thermal conductivity, $\mathrm{W} / \mathrm{m}-\mathrm{K}$

L: Length, $\mathrm{m}$

$\mathrm{m}$ : Mass flow rate, $\mathrm{kg} / \mathrm{s}$

$\mathrm{N}_{\mathrm{b}}$ : number of baffles, dimensionless

$\mathrm{N}_{\mathrm{p}}$ : Number of passes, dimensionless

NTU: Number of transfer units, dimensionless

Nu: Nusselt number, dimensionless

Pr: Prandtl number, dimensionless

$\Delta \mathrm{P}$ : Pressure drop, $\mathrm{Pa}$

Re: Reynolds number, dimensionless 
$\mathrm{R}_{\mathrm{f}}$ : Fouling factor, $\mathrm{m}^{2} \mathrm{~K} / \mathrm{W}$

$\mathrm{T}$ : Temperature, $\mathrm{K}$

$\mathrm{U}$ : Overall heat transfer coefficient, $\mathrm{W} / \mathrm{m}^{2} \mathrm{~K}$

v: actual velocity, $\mathrm{m} / \mathrm{s}$

V: volumetric flow, $\mathrm{m}^{3} / \mathrm{s}$

$\mathrm{x}_{\mathrm{f}}$ : Thickness of deposit material, $\mathrm{m}$

\section{Greek letters}

$\beta$ : chevron angle

$\varepsilon$ : Effectiveness

$\rho:$ Density, $\mathrm{Kg} / \mathrm{m}^{3}$

$\mu$ : Viscosity, N-s/m²

\section{Subscripts and superscripts}

c: cold

h: hot

i: inlet

max: maximum

min: minimum

o: outlet

t: tubes

w: wall 


\section{Introduction}

Externally fired gas turbines (EFGT) are an interesting option for electricity and heat production due to their configuration. In externally fired gas turbines, combustion takes place outside the cycle at atmospheric pressure. Flue gas coming from the combustor heats the compressed air in a heat exchanger. The resulting hot, clean and compressed air is later expanded in a turbine. This configuration allows the use of a variety of fuels since the flue gas is not in direct contact with the turbine [1].

The configuration of externally fired gas turbines represents an option for utilizing biomass gasification gas. Biomass gasification gas has encountered difficulties in finding a conversion technology capable to deal with its contaminants [2]. These contaminants are particulates, alkali metals, tars, sulfur and chlorine. They can cause erosion, hot corrosion, clogging and depositions internally [3]. Cleaning steps are recommended prior to using gasified biomass in internal combustion engines and standard gas turbines, where combustion takes place as part of the cycle [4]. However, the addition of cleaning steps after gasification has made it a complex and costly system [2]. Instead, externally fired gas turbines offer an opportunity for biomass gasification gas reducing strict fuel quality requirements by switching the flue gases to the heat exchanger, and thus avoiding direct contact with the turbine [1], [2].

The heat exchanger is the main component in externally fired gas turbines. The heat exchanger should be able to deal with the conditions of the flue gases from biomass gasification gas and operate at high temperatures for long periods of time.

Additionally, the cold side outlet temperature from the heat exchanger corresponds to the turbine inlet temperature (TIT). Theoretically, a higher turbine inlet temperature increases the efficiency of the cycle. As a result, the selection of a heat exchanger type that can handle these conditions is important. The size, the temperatures, the fluids, the geometry, and other factors influence its performance.

There are various studies of different types of heat exchangers to be used in externally fired gas turbines. Zimmerman et al. [5] proposed a pebble heater when using combustion of solid biomass in an externally fired gas turbine system. The pebble heater was able to work up to $950^{\circ} \mathrm{C}$ [5]. A bayonet tube heat exchanger with internal 
fins was suggested by Zeng et al. [6] for high temperature applications. Gaderer et al. [7] suggested a heat exchanger immersed in a fluidized bed combustor when using solid biomass. This concept was chosen in order to reduce fouling and increase heat transfer.

Chu et al. [8] studied the flow nonuniformity of a plate-fin heat exchanger for high temperature applications. The effect of inclined, helical, and segmented baffles added at the inlet were compared. The addition of helical baffles changing the pitch equidifferently reduced the flow nonunformity, increased the Nusselt number and pressure drop [8]. Ma et al. [9] investigated the thermo-hydraulic performance of a ribbed channel in a heat exchanger. It was found that the heat transfer was improved with increasing the rib height and pressure drop was higher when the inlet temperature increased [9]. Nagarajan et al. [10] developed a novel ceramic plate-fin heat exchanger using CFD simulations. The thermal and hydraulic performances of nine different fin designs were compared for high temperature applications [10]. Monteiro and Batista de Mello [11] studied a ceramic offset strip fin heat exchanger for high temperature applications using CFD simulations. Correlations for Colburn and friction factors were found for the heat exchanger studied [11]. Additionally, varying the geometrical dimensions of the heat exchanger suggested, the effect of pressure drop and effectiveness on the net electrical efficiency of an externally fired gas turbine cycle was analyzed. The results showed that the effectiveness of the heat exchanger had a stronger influence than the pressure drop on the efficiency of the cycle studied [12]. Ma et al. [13] analyzed the heat transfer and pressure drop performances of an offset-bubble primary surface channel. The study was focused on the surface structure and geometrical parameters [13]. Cordiner et al. [14] proposed a high-temperature flat plate fin heat exchanger coupled to a furnace for a prototype power plant based on an externally fired gas turbine. The objective was to take advantage of radiative and convective heat transfer. The prototype was modeled with the proposed heat exchanger. The power output and efficiency were evaluated with different characteristics of the fuel. A control of the biomass characteristics in terms of higher heating value was found to be very important to reduce its impact on the performance of the prototype studied [14]. 
Al-attab and Zainal [15] suggested a shell and tube heat exchanger as more suitable for externally fired gas turbines when using biomass gasification gas due to fouling and maintenance concerns. The choice of the type of heat exchanger was based on the small particles, ash fraction and tars that can cause fouling and block passages in the heat exchanger. The results showed that the recommended shell and tube heat exchanger reached turbine inlet temperatures of $694^{\circ} \mathrm{C}$ and $62.5 \%$ of effectiveness [15]. Iora and Silva [16] proposed two shell and tube heat exchangers arranged in series for an externally fired gas turbine. This selection was justified due to fouling in the hot side. A $50 \mathrm{~kW}$ plant with a turbine inlet temperature of $750^{\circ} \mathrm{C}$ was analyzed and an electrical efficiency of $20 \%$ was reported [16].

Several studies are focused on the development of novel plate heat exchangers that are able to operate at high temperatures with low pressure drops. However, the use of biomass gasification gas in externally fired gas turbines implies not only the thermal and hydraulic performance of heat exchangers, but also their ability to handle fuels with components that can deposit in heat transfer surfaces. For this reason, shell and tube heat exchangers were suggested as more adequate for such applications. In order to provide insight of the application of a suitable heat exchanger for such systems, this work studies the effect of deposit materials on pressure drop and effectiveness of two heat exchanger types (i.e., a two-tube-passes shell and tube heat exchanger and a corrugated plate heat exchanger) that were tested in two different externally fired gas turbine prototypes.

\section{Methodology}

Two heat exchangers are compared through simulations using Matlab [17] and Aspen Plus [18] in the context of an externally fired gas turbine prototype built by Compower $A B$. This prototype was built using a corrugated plate heat exchanger to transfer heat from the flue gases to the compressed air. Data provided by Compower $A B$ was used to find a correlation for the corrugated plate heat exchanger to understand the effect of increasing deposit materials on its heat transfer surfaces. A description of the corrugated plate heat exchanger geometry is given in section 2.2.1. A two-tube-passes shell and tube heat exchanger was suggested as more suitable due to fouling by Al- 
attab and Zainal [15]. The effectiveness and pressure drop of this heat exchanger with increasing the thickness of deposit materials were also evaluated under the operational conditions of the corrugated plate heat exchanger and the externally fired gas turbine prototype built by Compower AB. A description of the two-tube passes shell and tube heat exchanger is shown in section 2.2.2.

\subsection{Operational conditions of the externally fired gas turbine prototype}

A scheme of the externally fired gas turbine prototype from Compower $A B$ is shown in Figure 1. First, air is drawn into a compressor. After the compressor, the air enters a high temperature heat exchanger and finally it expands in a turbine. Combustion takes place outside the cycle, at atmospheric pressure. Biogas was used as fuel in the tests. Heat is transferred from the hot flue gas to the compressed air.

The operational conditions in which both heat exchangers were simulated are based on experimental data provided by Compower $A B$. These parameters are presented in Table 1.

As the measurements were carried out for other purposes, the test data was incomplete. For the cold side, the test data included measurements of temperature and mass flow rate, stream 1 in Figure 1. For the hot side, the parameters were calculated based on related measured values. The fuel flow rate to the combustor was measured while the air was injected with $20 \%$ of excess air. The mass flow rates of the hot side were calculated based on the air and fuel flow for the combustion and the air flow that recirculates from the turbine exit, stream 4 from Figure 1. The inlet temperatures for the hot side were also calculated based on the temperature of the combustion products and the measured temperature of the exhaust air from the turbine, stream 4 from Figure 1. The outlet temperature of the hot side was calculated with an energy balance between the cold and hot side assuming that the heat gained by the cold side is equal to the heat transferred by the hot side. Based on these calculations the effectiveness of the heat exchanger was determined using Equation 1.

$$
\varepsilon=\frac{T_{c, o}-T_{c, i}}{T_{h, i}-T_{c, i}}
$$




\subsection{Heat exchangers}

\subsubsection{Corrugated plate heat exchanger}

The plate heat exchanger for the evaluation is a corrugated type with the gas and airflows mainly opposing each other. More information about the heat exchanger can be found in Lagerström and Xie [19]. A scheme of the heat exchanger is shown in Figure 2.

The heat exchanger is comprised of 60 parallel channels. The main characteristic dimensions of the heat exchanger are presented in Table 2.

\subsubsection{Two-tube-passes shell and tube heat exchanger}

The geometrical information for the shell and tube heat exchanger was obtained from the studies carried out by Al-attab and Zainal [15]. The heat exchanger is a two-pass cross flow type. The main dimensions of the heat exchanger are given in Table 3.

A scheme of the shell and tube heat exchanger is shown in Figure 3. The figure was adapted from Al-attab and Zainal [15].

\subsection{Model of the heat exchangers}

The NTU method was used for modeling the heat exchangers [20]. A short description of the procedure is summarized below.

A value of effectiveness $(\varepsilon)$ was assumed to start calculation of outlet temperatures. The outlet temperatures can then be calculated using the equations:

$$
\begin{gathered}
T_{h, o}=T_{h, i}-\varepsilon \frac{C_{\min }}{C_{h}}\left(T_{h, i}-T_{c, i}\right) \\
T_{c, o}=T_{c, i}-\varepsilon\left(T_{h, i}-T_{c, i}\right)
\end{gathered}
$$

Where $\mathrm{C}_{\min }$ is the minimum heat capacity and corresponds to $\mathrm{C}_{\mathrm{c}}$.

Initially, it was assumed that:

$$
C_{c} / C_{h} \approx \dot{m}_{c} / \dot{m}_{h}
$$


With the calculated temperatures, the properties such as heat capacity, viscosity, density and thermal conductivity were calculated using the mean temperature between the inlet and outlet. With the calculated properties, iterations were carried out correcting $\mathrm{C}_{\mathrm{c}}$ and $\mathrm{C}_{\mathrm{h}}$, calculating the new temperatures and subsequently calculating the new properties, where $C_{c}$ and $C_{h}$ can be calculated using:

$$
\begin{aligned}
C_{c} & =\dot{m}_{c} c_{p c} \\
C_{h} & =\dot{m}_{h} c_{p h}
\end{aligned}
$$

Then Reynolds, Prandtl and Nusselt number were calculated using the following equations:

$$
R e=\frac{\rho v d_{e}}{\mu}
$$

The Prandtl number:

$$
\operatorname{Pr}=\frac{\mu c_{p}}{k}
$$

The Nusselt number:

$$
N u=\frac{h d_{e}}{k}
$$

The properties were evaluated using the mean temperature between inlet and outlet for each fluid. The heat transfer coefficients were calculated using the corresponding empirical correlations as indicated in sections 2.3.1 and 2.3.2.

With the heat transfer coefficients, the overall thermal resistance was calculated using the equation below:

$$
\begin{gathered}
\frac{1}{U A}=R_{h}+R_{h, f}+R_{w}+R_{c, f}+R_{c} \\
\frac{1}{U A}=\frac{1}{(h A)_{h}}+R_{h, f}+R_{w}+R_{c, f}+\frac{1}{(h A)_{c}}
\end{gathered}
$$


Where $R_{h, f}$ is the thermal resistance due to fouling for the hot side, $R_{c, f}$ is the thermal resistance due to fouling for the cold side, $R_{w}$ is the wall thermal resistance, $h_{h}$ and $h_{c}$ are the heat transfer coefficients for the hot and cold sides and $A_{h}$ and $A_{c}$ are the heat transfer areas for the hot and cold sides respectively.

From the calculated properties, $\mathrm{C}^{*}$ was found using the following equation:

$$
C^{*}=C_{\min } / C_{\max }
$$

From the calculated UA value, the number of transfer units (NTU) can be calculated using:

$$
N T U=U A / C_{\min }
$$

Using the NTU value, the effectiveness was calculated. For the plate heat exchanger and considering counter flow the following equation was used:

$$
\varepsilon=\frac{1-e^{\left[-N T U\left(1-C^{*}\right)\right]}}{1-C^{*} e^{\left[-N T U\left(1-C^{*}\right)\right]}}
$$

For the shell and tube heat exchanger with one shell and two tube passes the following equation was used [21]:

$$
\varepsilon=\frac{2}{1+C^{*}+\left[\left(1+C^{* 2}\right)^{1 / 2} * \frac{1+e^{\left[-(N T U) *\left(1+C^{* 2}\right)^{1 / 2}\right]}}{1-e^{\left[-(N T U) *\left(1+C^{* 2}\right)^{1 / 2}\right]}}\right]}
$$

With the calculated effectiveness $(\varepsilon)$, all the steps were recalculated from Equation 2. The iterative process continued until the assumed and calculated values converged.

\subsubsection{Correlation for the corrugated plate heat exchanger}

In order to evaluate the heat transfer performance of the corrugated plate heat exchanger, an empirical correlation was adjusted to fit the data. First, an experimental overall heat transfer coefficient was calculated based on the parameters provided in 
Table 1. Reynolds, Prandtl, and Nusselt numbers were also calculated. Using these results a calculated overall heat transfer coefficient was found. The calculated value was compared with the experimental value. Then, the coefficients of the correlations were adjusted so the relative errors between the experimental and calculated overall heat transfer coefficients were small. The correlation from Bogaert and Bölcs [22] was used to fit the data.

The original correlation of Bogaert and Bölcs [22] was:

$$
N u=0.26347 e^{0.7152} \operatorname{Pr}^{\frac{1}{3} e^{\frac{6,4}{P r+30}}}\left(\frac{\mu}{\mu_{w}}\right)^{\frac{0.3}{(R e+6)^{0.125}}}
$$

For $\operatorname{Re}>80$

The average temperature between inlet and outlet for each side was assumed to be the same as the wall temperature of each respective side. The last term in Equation 12 was assumed to be close to unity.

The correlation adjusted to the data was:

$$
N u=0.1212 R e^{0.65888} \operatorname{Pr}^{\frac{1}{3} e^{\frac{6,4}{P r+30}}}
$$

For $\operatorname{Re}>80$

The correlation showed to agree between 0.37 to $3 \%$ the operation range of interest. Since the correlation was fitted to the data, the error is expected to be small. The differences in the parameters of the fitted and original correlations (i.e., Equations 12 and 13) are attributed to differences in similar but not identical geometry of both heat exchangers. Some data tests from the prototype, calculated parameters and their relative errors are shown in Table 4.

The pressure drop was evaluated using the Darcy Weisbach equation.

$$
\Delta P=f \frac{L}{d_{h}} \frac{\rho v^{2}}{2}
$$

For laminar flow: 


$$
f=\frac{64}{R e}
$$

\subsubsection{Correlation for the two-tube-passes shell and tube heat exchanger}

In order to compare both heat exchangers, the heat transfer area was kept constant in both cases. An equal heat transfer area was chosen as a parameter for comparison since the area is related to the cost of the heat exchanger. Cost itself was not used in the comparison because it is a difficult parameter as the values are uncertain since the heat exchangers for the externally fired micro gas turbine are not yet in volume production. The original length of the shell and tube heat exchanger was $1.5 \mathrm{~m}$ giving a heat transfer area of $8 \mathrm{~m}^{2}$. However, the heat transfer area for the plate heat exchanger was about $10.33 \mathrm{~m}^{2}$. For the purpose of this study, the length of the shell and tube heat exchanger was increased in the simulation to keep about the same heat transfer area for both cases. The correlations for heat transfer evaluation of the shell and tube heat exchanger were obtained from Ramesh and Dusan [20] according to Alattab and Zainal [15]. The same correlations were used in this study.

The correlation for the air side (tubes side) was the Dittus-Boelter equation:

$$
N u=0.024 \operatorname{Re}^{0.8} \operatorname{Pr}^{0.4}
$$

For the gas side (shell side) the following correlation was used:

$$
N u=1.04 \operatorname{Re}^{0.4} \operatorname{Pr}^{0.36}\left(\operatorname{Pr} / \operatorname{Pr}_{w}\right)^{0.25}
$$

The pressure drop for the tubes side was evaluated using the equation below [23]:

$$
\Delta P=\left(\frac{f * L_{t}}{d_{i}}+1\right) N_{p} \frac{1}{2} \rho * v^{2}
$$

Equation 15 can be used to calculate the friction factor for laminar flow while for turbulent flow the following equation can be used [23]:

$$
f=(0.790 \ln (R e)-1.64)^{-2}
$$


The pressure drop for the shell side was evaluated using the equation below [23]:

$$
\Delta P=f \frac{D_{s}}{D_{e}} *\left(N_{b}+1\right) \frac{1}{2} \rho * v^{2}
$$

Where the friction factor can be calculated from:

$$
f=e^{(0.576-0.19 \ln (R e))}
$$

\subsubsection{Fouling factor and thickness of the deposit material}

The thickness of the deposit material was varied in the simulation, resulting in a variation of the thermal resistance due to fouling [22]. The relation used for this purpose was:

$$
R_{f}=\frac{x_{f}}{k_{f}}
$$

Where $x_{f}$ is the thickness of the deposit material, $k_{f}$ is the thermal conductivity of the deposit material and $R_{f}$ is the thermal resistance due to fouling.

Different thicknesses of deposit material were considered together with a range of thermal conductivities. The range of thermal conductivities varied from 0.07 [24] to 3.8 $\mathrm{W} / \mathrm{m}-\mathrm{K}[26]$. This range was selected based on the thermal conductivities of some materials that can be present after combustion of biomass gasification gas and that can deposit on heat transfer surfaces such as soot and alkali metals [3].

The thermal resistance due to fouling for the cold side was assumed to be constant since filtered air was used in the tests. For the plate heat exchanger, this value was assumed to be one tenth of the corresponding value of fouling coefficient for compressed air of the TEMA standards. This assumption is recommended for plate heat exchangers [27]. For the shell and tube heat exchanger the fouling factor for compressed air from the TEMA standards was used [28]. 


\section{Results and discussion}

\subsection{Effectiveness of the heat exchangers}

In Figures $4 a$ and $4 b$, the effectiveness of the heat exchangers is plotted against a range of thicknesses of deposit material at different thermal conductivities. As can be seen, at small thicknesses of deposit material, there is a slight variation of effectiveness for all the range of thermal conductivities. At larger thicknesses of deposit materials, the difference in effectiveness is increased between materials with low and high thermal conductivity. This is because the properties characteristics of the deposit materials have a larger effect in heat transfer at larger thicknesses of deposit materials.

From Figures $4 a$ and $4 b$, it can also be observed that although the effectiveness of the two-tube-passes shell and tube heat exchanger is lower compared to the corrugated plate heat exchanger, the thickness of the deposit material affects more the effectiveness of the plate heat exchanger. This is only seen for large thickness of deposits (e.g., $0.7 \mathrm{~mm}$ ) for all the range of thermal conductivities. Additionally, a decrease in effectiveness is observed for deposits with lower thermal conductivity while a slight increase is observed for materials with higher thermal conductivity. It is important to mention, that alternative designs of shell-tube and plate heat exchangers can have different effectiveness and different response to deposit materials.

Figures 5 and 6 show the heat transfer coefficient and the resistance to heat transfer due to fouling versus the thickness of deposit materials for two thermal conductivities. As can be seen, the heat transfer coefficient $\left(h_{h}\right)$ increases with increasing the thickness of deposit materials. This is due to an increase in the velocity of the fluid because of a reduction in the hydraulic diameter. However, for low thermal conductivities the resistance to heat transfer due to fouling $\left(R_{f}\right)$ is much larger than the resistance due to heat transfer $\left(R_{h}\right)$. The resistance due to fouling dominates over the resistance due to heat transfer even though the heat transfer coefficient increases. For high thermal conductivities, the resistance to heat transfer due to fouling $\left(R_{f}\right)$ is smaller than the resistance due to convection $\left(R_{h}\right)$. The resistance due to convection dominates over the resistance due to fouling. It can be said that the deposit material 
has two effects in heat exchangers. On one hand an increase in the resistance to heat transfer causing a reduction of effectiveness and on other hand a decrease of the through flow area causing an increase in the velocity of the fluid and as a result an increase in the heat transfer coefficient. The last effect can be influenced by the relationship between the pumping system and the resistance of the fluid [30].

Figure 7 show the effectiveness versus the thickness of deposit material for different plate distances and different diameter of the tubes. As can be seen in Figure 7a, for the corrugated plate heat exchanger, the effectiveness is higher as the plate distance is shorter. This is due to a higher velocity as the hydraulic diameter reduces with shorter plate distances. For the two-tube-passes shell and tube heat exchanger (Figure 7b), the effectiveness is higher as the tube diameter increases. This is because the through flow area of the hot side is reduced as the tube diameter increases and the velocity of the hot side mass flow rate increases.

\subsection{Pressure drop of the heat exchangers}

Figures $8 \mathrm{a}$ and $8 \mathrm{~b}$ show the influence of the increment in the thickness of deposit material on the pressure drop of the hot side of the corrugated plate heat exchanger and the two-tube-passes shell and tube heat exchanger. An exponential tendency is observed in the increment of pressure drop for the corrugated plate heat exchanger, while a linear trend can be seen for the two-tube-passes shell and tube heat exchanger. This is due to the narrow passages in the plate heat exchanger. The increase of the thickness deposit reduces even more the hydraulic diameter in the heat exchanger resulting in an exponential increase of pressure drop.

In Figure 8a, it can also be observed that small increases in the thickness of the deposit after $0.5 \mathrm{~mm}$ lead to a steep increase of the pressure drop for all the range of thermal conductivities. However, the effectiveness after the same point is not influenced in the same way as the pressure drop, see Figure 4a. For the case of the two-tube-passes shell and tube heat exchanger, Figure $8 \mathrm{~b}$, a steep increase in pressure drop is not observed even at a thickness in the range of $2 \mathrm{~mm}$. This is due to the geometrical configuration of the two-tube-passes shell and tube heat exchanger compared with the corrugated plate heat exchanger. 
Figures $8 \mathrm{a}$ and $8 \mathrm{~b}$ also show that for the same thickness of deposit material, the increment in pressure drop is lower for the two-tube-passes shell and tube heat exchanger than for the corrugated plate heat exchanger. This is due to the narrow passages in plate heat exchangers and the difference in hydraulic diameters.

Figure 9 shows the increment of pressure drop versus the thickness of deposit material varying the plate distance for the corrugated plate heat exchanger and the tube diameter for the two-tube-passes shell and tube heat exchanger. As can be seen, there is an increase of pressure drop as the thickness of deposit material increases. For the corrugated plate heat exchanger (i.e., Figure 9a) with a plate distance of $1 \mathrm{~mm}$, the increment in pressure drop increases steeply after $0.5 \mathrm{~mm}$ while for a plate distance of 1.5 and $2 \mathrm{~mm}$ the increment in pressure drop increases slowly. Under these conditions, the increase of pressure drop for a plate distance of $1 \mathrm{~mm}$ is about 27 times that of a plate distance of $2 \mathrm{~mm}$ and 8.3 times the increment of pressure drop of a plate distance of $1.5 \mathrm{~mm}$. For the two-tube passes shell and tube heat exchanger, Figure $9 b$, the pressure drop is low for all the tube diameters in all the range of thickness of deposit materials studied. However, the highest increment of pressure drop is given for the tube diameter of $25 \mathrm{~mm}$. This is due to a reduced through flow area for the shell side when the diameter of the tube increases.

Batista de Mello [12] reported pressure drops in the range of 596 to 6500 Pa (i.e., 5.96 to $65 \mathrm{mbar}$ ) for a ceramic offset strip fin heat exchanger under clean conditions and with a hot side mass flow rate of about $0.79 \mathrm{~kg} / \mathrm{s}$. The pressure drops presented in this study are lower even considering the deposit materials and the narrower passages in the heat exchanger geometry. However, the mass flow rate in this study is about eight times lower than the one considered by Batista de Mello [12]. The difference in geometry of the heat exchangers also influences the results.

\subsection{Power output of the cycle}

Figure 10 shows the power output of the externally fired gas turbine prototype versus the thickness of deposit materials for different plate distances of the corrugated plate 
heat exchanger. As can be seen, a higher power output is seen for a plate distance of 1 $\mathrm{mm}$ than 1.5 and $2 \mathrm{~mm}$. This is expected since at shorter plate distances, there are higher velocities resulting in higher heat transfer coefficients and higher turbine inlet temperatures. It can also be seen that the power output reduces as the thickness of deposit material increases for all the plate distances. This is because the increase of thickness of deposit materials results in a decrease in the pressure ratio of the turbine by increasing the pressure drop in the heat exchanger. This results in a reduction of the power output. Additionally, there is a decrease in the turbine inlet temperature as a result of a decrease in the effectiveness of the heat exchanger due to an increase of the thickness of deposit materials. This also contributes to reducing the power output. This can be seen in Figure 11. Under clean conditions, the power output at a plate distance of $1 \mathrm{~mm}$ is 1.7 times higher than the power output at a plate distance of 1.5 $\mathrm{mm}$ and 2.7 times higher than the power output at a plate distance of $2 \mathrm{~mm}$. At a thickness of deposit material of $0.3 \mathrm{~mm}$, the power output at a plate distance of $1 \mathrm{~mm}$ decreases in $25 \%$ while for a plate distance of $2 \mathrm{~mm}$ the power output decreases in $40 \%$. Under the same conditions, the turbine inlet temperature reduces in 2.6 to $2.2 \%$ for a plate distance of 1 and $2 \mathrm{~mm}$ respectively. Instead the pressure ratio reduces in $0.85 \%$ to $0.04 \%$ for the same plate distances. From this, it can be said that the effectiveness of the heat exchanger has a stronger effect on the power output of the cycle than the pressure drop. These results are in agreement with the results reported by Batista de Mello [12].

Under the operating conditions of the externally fired gas turbine prototype, the twotube-passes shell and tube heat exchanger showed low power outputs. This is due to the temperature limit imposed for operation of the heat exchanger $650^{\circ} \mathrm{C}$.

\section{Conclusions}

In this work, two heat exchangers were compared considering the effect of deposit materials on heat transfer surfaces. The heat exchangers were compared in the context of an externally fired gas turbine prototype. The thermal conductivity of the deposit materials was varied in a range that can be found in potential deposit materials from the combustion of biomass gasification gas. The effect of varying the 
plate distances for the corrugated plate heat exchanger and varying tube diameters for the two-tube-passes shell and tube heat exchanger was analyzed. The final effect of changing these parameters in the power output was also reported. The conclusions are as follows:

- At larger thicknesses of deposit materials, the effectiveness of the corrugated plate heat exchanger is more affected than the effectiveness of the two-tubepasses shell and tube heat exchanger.

- The increase in the thickness of deposit material has two effects. On one hand, an increase in the heat transfer resistance; reducing the effectiveness of the heat exchanger and on the other hand, a reduction of the hydraulic diameter; increasing the velocity of the flow and hence increasing the heat transfer coefficient.

- There is an exponential increase of pressure drop for the corrugated plate heat exchanger while a linear trend is shown for the two-tube-passes shell and tube heat exchanger.

- The increment of pressure drop due to deposit materials is much higher for short plate distances for the corrugated plate heat exchanger. For the twotube-passes shell and tube heat exchanger, the pressure drop of the hot side is very small even when reducing the through flow area.

- The effectiveness of the heat exchangers studied had a stronger effect on the power output than the pressure drop.

In application for externally fired gas turbines, the selection of a material capable to withstand high temperatures can be more challenging for the two-tube-passes shell and tube heat exchanger due to their lower effectiveness compared to the corrugated plate heat exchanger. Its main advantage is still its ability to deal with contaminated fluids. Instead, for the corrugated plate heat exchanger, cleaning of the fuel gas to some extent may be required. In such a case, a cost analysis between the benefit of 
increasing the effectiveness of the heat exchanger and the cost of cleaning equipment for producer gas can be evaluated.

It is important to note that deposition of materials on heat transfer surfaces is a very complex process and it is unique in each type of heat exchanger depending on several factors such as design, shear stress, velocity of the fluids, composition, surface roughness, and in this case, the performance of the combustion process itself can also have an influence. Corrosion is another important factor when dealing with heat exchangers exposed to flue gases. However, corrosion is outside the scope of this study. The results of this work are important when considering the performance of a heat exchanger for an externally fired gas turbine. An experimental investigation is recommended as future work taking into account all the conditions of a gasification system and the growth rate of deposit materials over time.

\section{Acknowledgements}

The financial support of the Swedish International Development Cooperation Agency (SIDA), the division of Heat and Power Technology, Department of Energy Technology at Royal Institute of Technology (KTH) in Sweden, and Universidad Mayor de San Simon (UMSS) in Bolivia is acknowledged for this work. The EXPLORE Polygeneration project being a part of STandUP for Energy and KIC Innoenergy are also acknowledged for providing test data.

\section{References}

[1] M. Kautz and U. Hansen, "The externally-fired gas-turbine (EFGT-Cycle) for decentralized use of biomass," Appl. Energy, vol. 84, no. 7-8, pp. 795-805, Jul. 2007.

[2] D. Vera, F. Jurado, and J. Carpio, "Study of a downdraft gasifier and externally fired gas turbine for olive industry wastes," Fuel Process. Technol., vol. 92, no. 10, pp. 1970-1979, Oct. 2011. 
[3] A. V Bridgwater, "The technical and economic feasibility of biomass gasification for power generation," Fuel, vol. 74, no. 5, pp. 631-653, 1995.

[4] M. Asadullah, "Barriers of commercial power generation using biomass gasification gas: A review," Renew. Sustain. Energy Rev., vol. 29, pp. 201-215, Jan. 2014.

[5] P. Zimmermann, A. Cardenas, C. Hirsch, and T. Sattelmayer, "Simulation of a micro turbine's dynamic behavior in a biomass incineration power plant based on the pebble heater technology," in Proceedings of ASME TURBOEXPO, 2009, pp. 93-102.

[6] M. Zeng, T. Ma, B. Sundén, M. B. Trabia, and Q. Wang, “Effect of lateral fin profiles on stress performance of internally finned tubes in a high temperature heat exchanger," Appl. Therm. Eng., vol. 50, no. 1, pp. 886-895, 2013.

[7] M. Gaderer, G. Gallmetzer, and H. Spliethoff, "Biomass fired hot air gas turbine with fluidized bed combustion," Appl. Therm. Eng., vol. 30, no. 13, pp. 15941600, Sep. 2010.

[8] W.-X. Chu, T. Ma, Z. Min, T. Qu, L. Wang, and Q. Wang, "Improvements on maldistribution of a high temperature multi-channel compact heat exchanger by different inlet baffles," Energy, 2014.

[9] T. Ma, Q. Wang, M. Zeng, Y. Chen, Y. Liu, and V. Nagarajan, "Study on heat transfer and pressure drop performances of ribbed channel in the high temperature heat exchanger," Appl. Energy, vol. 99, pp. 393-401, 2012.

[10] V. Nagarajan, Y. Chen, Q. Wang, and T. Ma, "Hydraulic and thermal performances of a novel configuration of high temperature ceramic plate-fin heat exchanger," Appl. Energy, vol. 113, pp. 689-602, 2014.

[11] D. B. Monteiro and P. E. B. De Mello, "Thermal performance and pressure drop in a ceramic heat exchanger evaluated using CFD simulations," Energy, vol. 45, no. 1, pp. 489-496, 2012. 
[12] P. E. B. De Mello and D. B. Monteiro, "Thermodynamic study of an EFGT (externally fired gas turbine) cycle with one detailed model for the ceramic heat exchanger," Energy, vol. 45, no. 1, pp. 497-502, Sep. 2012.

[13] T. Ma, M. Zeng, T. Luo, Y. Chen, and Q. Wang, "Numerical study on thermohydraulic performance of an offset-bubble primary surface channels," Appl. Therm. Eng., vol. 61, no. 1, pp. 44-52, 2013.

[14] S. Cordiner and V. Mulone, "Experimental-numerical analysis of a biomass fueled microgeneration power-plant based on microturbine," Appl. Therm. Eng., 2014.

[15] K. A. Al-attab and Z. A. Zainal, "Performance of high-temperature heat exchangers in biomass fuel powered externally fired gas turbine systems," Renew. Energy, vol. 35, no. 5, pp. 913-920, May 2010.

[16] P. lora and P. Silva, "Innovative combined heat and power system based on a double shaft intercooled externally fired gas cycle," Appl. Energy, vol. 105, pp. 108-115, 2013.

[17] Matlab R2013b, "Matlab." The MathWorks, Inc, Natick, Massachusetts, 2013.

[18] Aspen Plus v 8.0, “Aspen Plus ${ }^{\circledR}$. " Aspen Technolog, Inc, USA, 2012.

[19] G. Lagerström and M. Xie, "High performance and cost effective recuperator for micro-gas turbines," in Proceedings of ASME TURBOEXPO, 2002, pp. 1003-1007.

[20] S. K. Ramesh and S. P. Dusan, Fundamentals of heat exchanger design. New Jersey: Wiley \& Sons Inc, 2003, p. 976.

[21] F. P. Incropera, D. P. DeWitt, T. L. Bergman, and Lavine, Fundamentals of Heat and Mass Transfer, 6th ed. Hoboken, NJ: John Wiley \& Sons, 2006, p. 1024. 
[22] R. Bogaert and A. Bölcs, "Global performance of a prototype brazed plate heat exchanger in a large reynolds number range," Exp. Heat Transf., vol. 8, no. 4, pp. 293-311, Oct. 1995.

[23] H. S. Lee, Thermal Design: Heat sinks, thermoelectrics, heat pipes, compact heat exchangers and solar cells. New Jersey: Wiley \& Sons Inc, 2010, p. 648.

[24] J. E. Hesselgreaves, "An approach to fouling allowances in the design of compact heat exchangers," Appl. Therm. Eng., vol. 22, no. 7, pp. 755-762, May 2002.

[25] M. M. Awad, "Fouling of heat transfer surfaces," in Heat transfer - Theoretical analysis, experimental investigations and industrial systems, A. Belmiloudi, Ed. Rijeka, Croatia: InTech, 2011, pp. 505-542.

[26] Designed Institute for Physical Properties and AIChe, Knovel DIPPR Project 801 Full Version. Design Institute for Physical Property Research/AIChE, 2012.

[27] R. H. Perry and D. W. Green, Perry's Chemical Engineers' Handbook,, 8th ed. New York, USA: McGraw-Hill Professional, 2008, p. 2400.

[28] TEMA, Standards of the tubular exchanger manufacturers association, 8th ed. New York: Tubular exchanger manufacturers association Inc., 1999. 


\section{Figure captions}

Figure 1 Scheme of the externally fired gas turbine prototype

Figure 2 Scheme of the corrugated plate heat exchanger

Figure 3 Two-tube passes shell and tube heat exchanger. Figure adapted from Al-attab and Zainal [14].

Figure 4 Effectiveness versus thickness of the deposit material. a) Corrugated plate heat exchanger. b) Two-tube-passes shell and tube heat exchanger

Figure 5 Heat transfer coefficient and resistance to heat transfer due to fouling versus the thickness of deposit materials for the corrugated plate heat exchanger. a) For a thermal conductivity of $k=0.07 \mathrm{~W} / \mathrm{mK}$. b) For a thermal conductivity of $k=3.78 \mathrm{~W} / \mathrm{mK}$

Figure 6 Heat transfer coefficient and resistance to heat transfer due to fouling versus the thickness of deposit materials for the two-tube-passes shell and tube heat exchanger. a) For a thermal conductivity of $k=0.07 \mathrm{~W} / \mathrm{mK}$. b) For a thermal conductivity of $\mathrm{k}=3.78 \mathrm{~W} / \mathrm{mK}$

Figure 7 Effectiveness versus thickness of deposit materials. a) Different plate distances for the corrugated plate heat exchanger. b) Different diameter of the tubes for the two-tube-passes shell and tube heat exchanger

Figure 8 Increment of pressure drop versus thickness of deposit materials. a) Corrugated plate heat exchanger. b) Two-tube-passes shell and tube heat exchanger

Figure 9 Increment of pressure drop versus thickness of deposit materials. a) Different plate distances for the corrugated plate heat exchanger. b) Different diameter of the tubes for the two-tube-passes shell and tube heat exchanger

Figure 10 Power output versus thickness of deposit materials at different plate distances for the corrugated plate heat exchanger 
Figure 11 a) Pressure ratio and turbine inlet temperature versus thickness of deposit materials for $\mathrm{K}=0.07 \mathrm{~W} / \mathrm{m}-\mathrm{K}$. b) Pressure drop and effectiveness versus thickness of deposit materials for $\mathrm{K}=0.07 \mathrm{~W} / \mathrm{m}-\mathrm{K}$ 
Table 1 Operational conditions of the externally fired gas turbine prototype. Data was provided by Compower AB.

\begin{tabular}{lcc}
\hline Parameters & Value & Units \\
\hline Compressor isentropic efficiency & 0.70 & $\%$ \\
\hline Turbine isentropic efficiency & 0.76 & $\%$ \\
\hline Air mass flow rate to the compressor & 0.0916 & $\mathrm{~kg} / \mathrm{s}$ \\
\hline Compressor pressure ratio & 2.40 & - \\
\hline Turbine pressure ratio & 0.44 & - \\
\hline Exhaust air temperature from the turbine & 735.0 & $\mathrm{~K}$ \\
\hline Hot side inlet temperature to the heat exchanger* & 923.3 & $\mathrm{~K}$ \\
\hline Hot side outlet temperature of the heat exchanger* & 536.7 & $\mathrm{~K}$ \\
\hline Cold side inlet temperature to the heat exchanger & 409.6 & $\mathrm{~K}$ \\
\hline Cold side outlet temperature of the heat exchanger & 862.3 & $\mathrm{~K}$ \\
\hline Hot side mass flow rate* & 0.1050 & $\mathrm{~kg} / \mathrm{s}$ \\
\hline Effectiveness* & 0.88 & - \\
\hline Fuel mass flow rate** & 0.0014 & $\mathrm{~kg} / \mathrm{s}$ \\
\hline Farameters calculated from measured data & &
\end{tabular}

*Parameters calculated from measured data

$* *$ Biogas $65 \% \mathrm{CH}_{4}-35 \% \mathrm{CO}_{2}$ 
Table 2 Main dimensions of the heat exchanger. Source: Compower AB

\begin{tabular}{cc}
\hline Dimensions & Value \\
\hline Length $(\mathrm{mm})$ & 177 \\
\hline Width $(\mathrm{mm})$ & 394 \\
\hline Height $(\mathrm{mm})$ & 143 \\
\hline Amplitude of the corrugation, $\mathrm{b}(\mathrm{mm})$ & 1.0 \\
\hline Plate thickness, $\delta(\mathrm{mm})$ & 0.2 \\
\hline Number of channels per side & 60 \\
\hline Area (m $\left.{ }^{2}\right)$ & 10.3 \\
\hline Chevron angle $\beta$ & $13.5^{\circ}$ \\
\hline Wavelength (mm) & 3 \\
\hline Material of the heat exchanger & Stainless
\end{tabular}


Table 3 Main dimensions of the shell and tube heat exchanger [14].

\begin{tabular}{cc}
\hline Dimensions & Value \\
\hline Length $(\mathrm{m})$ & 1.5 \\
\hline Number of tubes & 64 \\
\hline Internal diameter $(\mathrm{mm})$ & 21 \\
\hline Thickness $(\mathrm{mm})$ & 2.5 \\
\hline Number of baffles & 4 \\
\hline Number of air passes & 2 \\
\hline Material of the heat exchanger & Stainless \\
\hline
\end{tabular}


Table 4 Data from tests of the manufacturer, calculated parameters and error of the model Data from tests of the prototype Calculated parameters

\begin{tabular}{|c|c|c|c|c|c|c|c|c|c|c|}
\hline \multicolumn{2}{|c|}{$\begin{array}{c}\text { Input } \\
\text { parameters }\end{array}$} & \multicolumn{3}{|c|}{$\begin{array}{c}\text { Output parameters } \\
\text { from tests data of the } \\
\text { manufacturer }\end{array}$} & \multicolumn{3}{|c|}{$\begin{array}{c}\text { Output parameters } \\
\text { calculated by the } \\
\text { model }\end{array}$} & \multicolumn{3}{|c|}{ Relative error \% } \\
\hline$T_{\text {gas }}$ & $\mathrm{T}_{\text {air }}$ & $T_{\text {gas }}$ & $\mathrm{T}_{\text {air }}$ & $\varepsilon$ & $T_{\text {gas }}$ & $T_{\text {air }}$ & $\varepsilon$ & $T_{\text {gas }}$ & $\mathrm{T}_{\text {air }}$ & $\varepsilon$ \\
\hline inlet & inlet & outlet & outlet & & outlet & outlet & & outlet & outlet & \\
\hline $\mathrm{K}$ & K & K & K & - & K & K & - & $\%$ & $\%$ & $\%$ \\
\hline 893.2 & 407.4 & 517.7 & 841.2 & 0.89 & 521.9 & 837.1 & 0.88 & 0.82 & 0.49 & 0.95 \\
\hline 903.9 & 407.8 & 527.5 & 845.8 & 0.88 & 526.6 & 846.8 & 0.88 & 0.17 & 0.11 & 0.22 \\
\hline 927.7 & 409.7 & 541.5 & 863.6 & 0.88 & 535.6 & 870.1 & 0.89 & 1.08 & 0.76 & 1.45 \\
\hline 936.5 & 415.2 & 556.7 & 866.1 & 0.86 & 544.8 & 879.1 & 0.89 & 2.13 & 1.50 & 2.89 \\
\hline
\end{tabular}




\section{Figure 1}

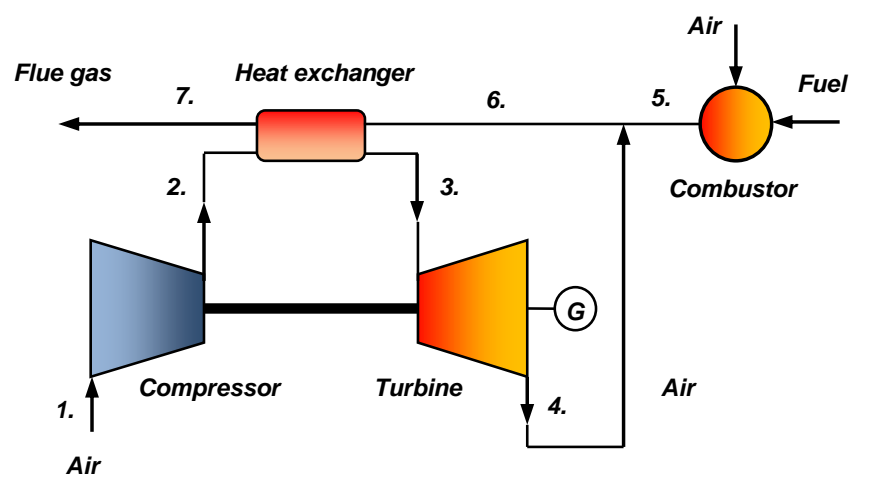




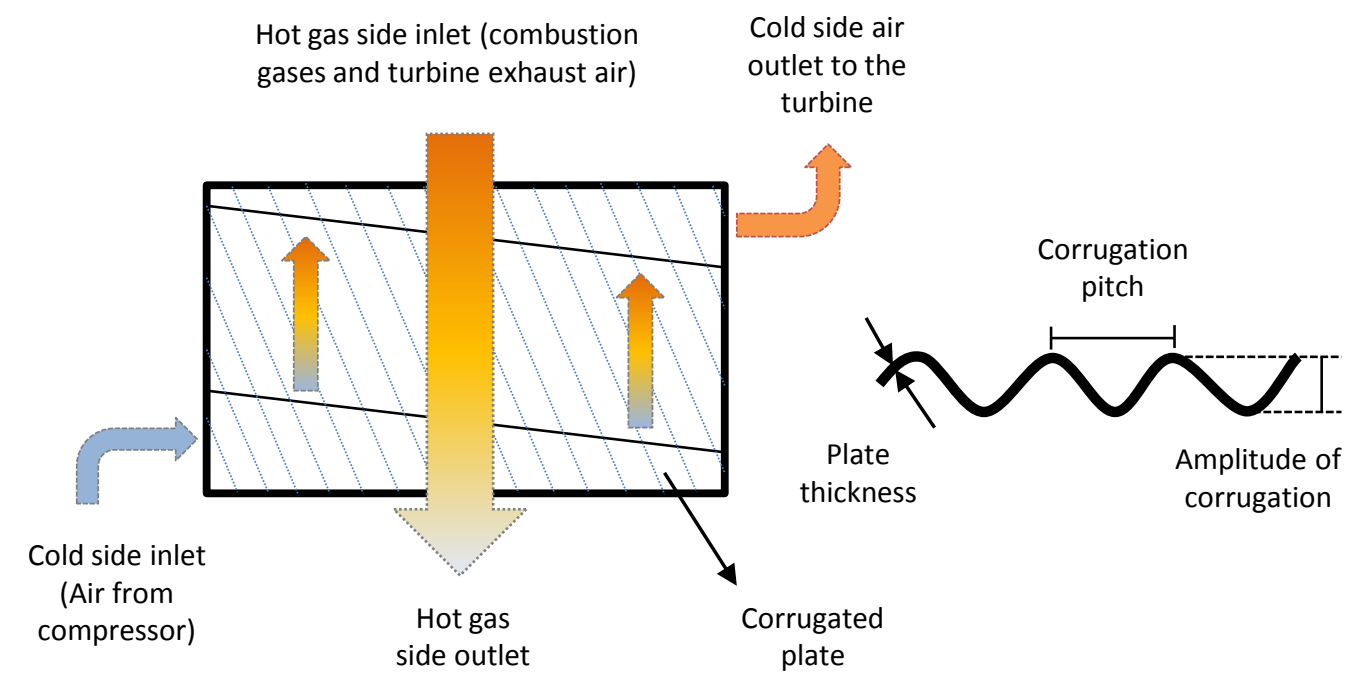




\section{Figure 3}

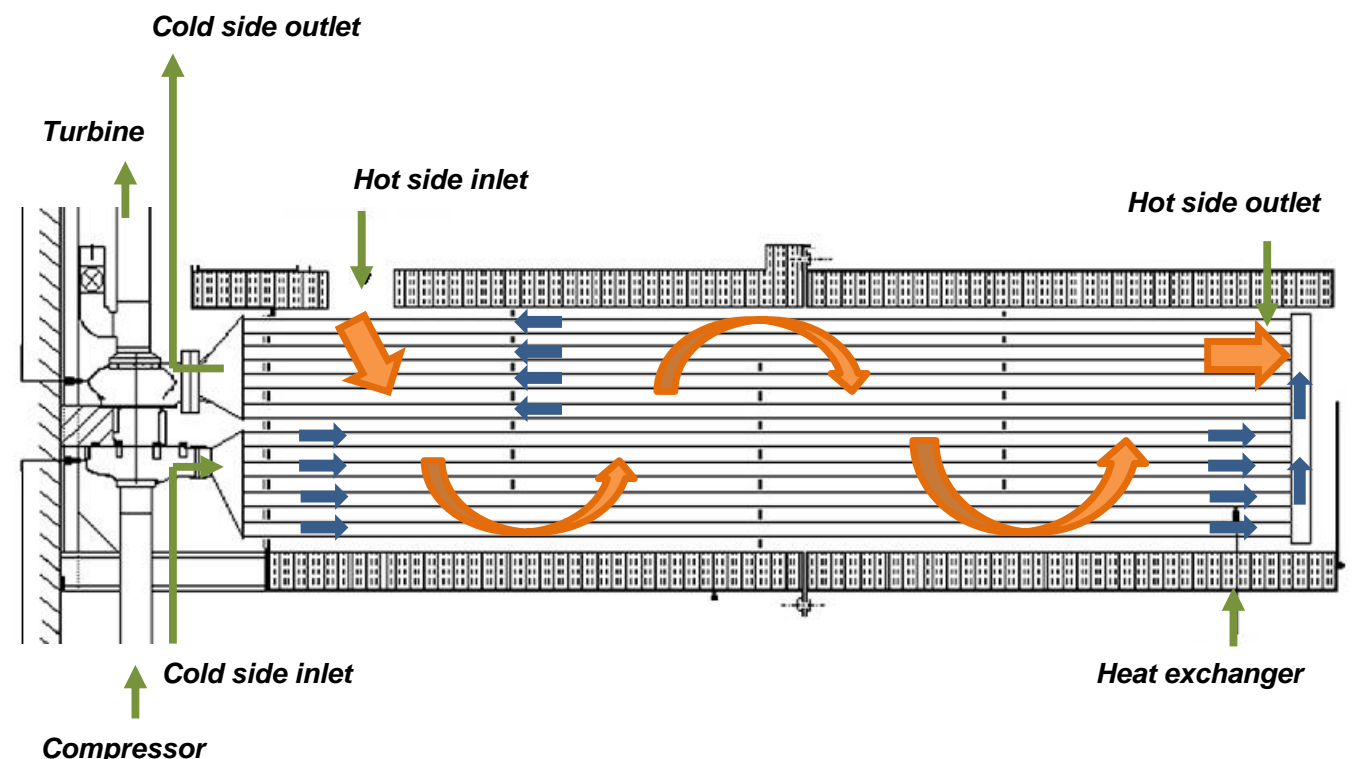

Compressor 
Figure 4

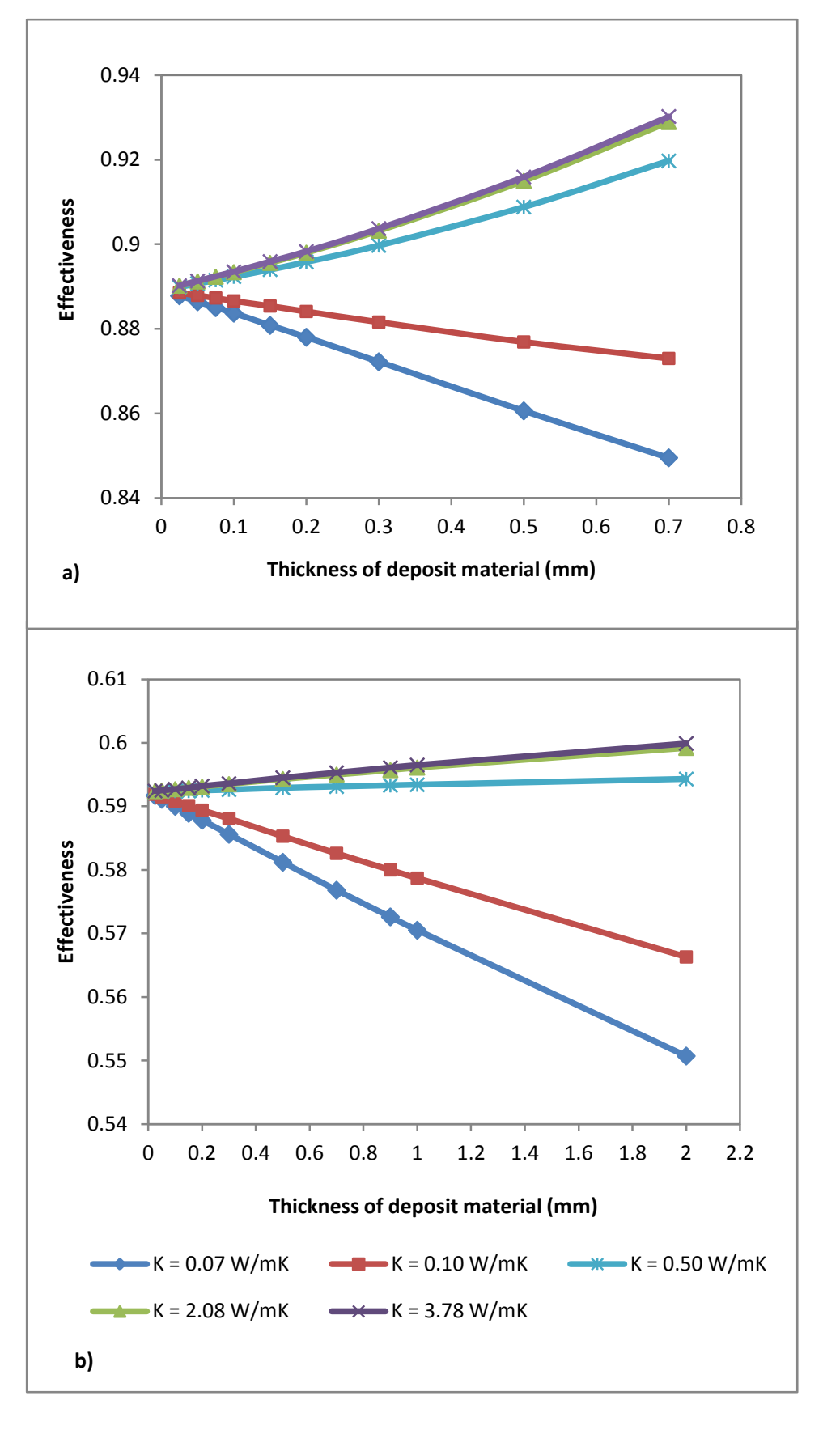

a)

$\longrightarrow \mathrm{K}=0.07 \mathrm{~W} / \mathrm{mK} \longrightarrow \mathrm{K}=0.10 \mathrm{~W} / \mathrm{mK} \longrightarrow \mathrm{K}=0.50 \mathrm{~W} / \mathrm{mK}$

b)

\section{Figure}

4
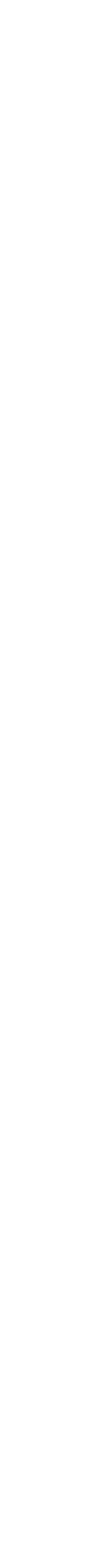
Figure 5

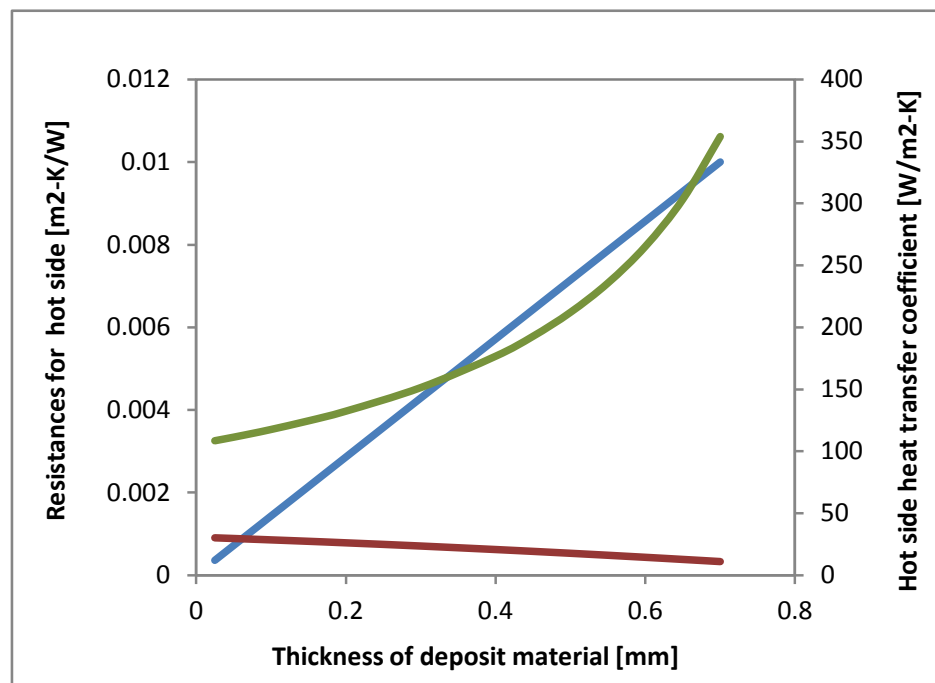

a) $k=0.07 \mathrm{~W} / \mathrm{m}-\mathrm{K}$

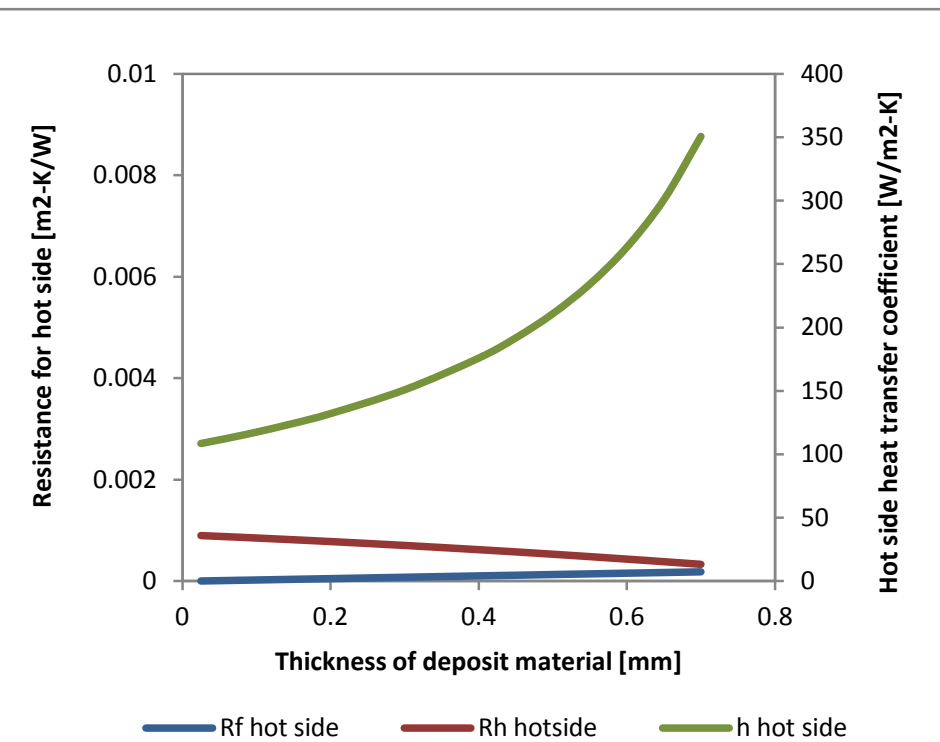

b) $k=3.78 \mathrm{~W} / \mathrm{m}-\mathrm{K}$ 


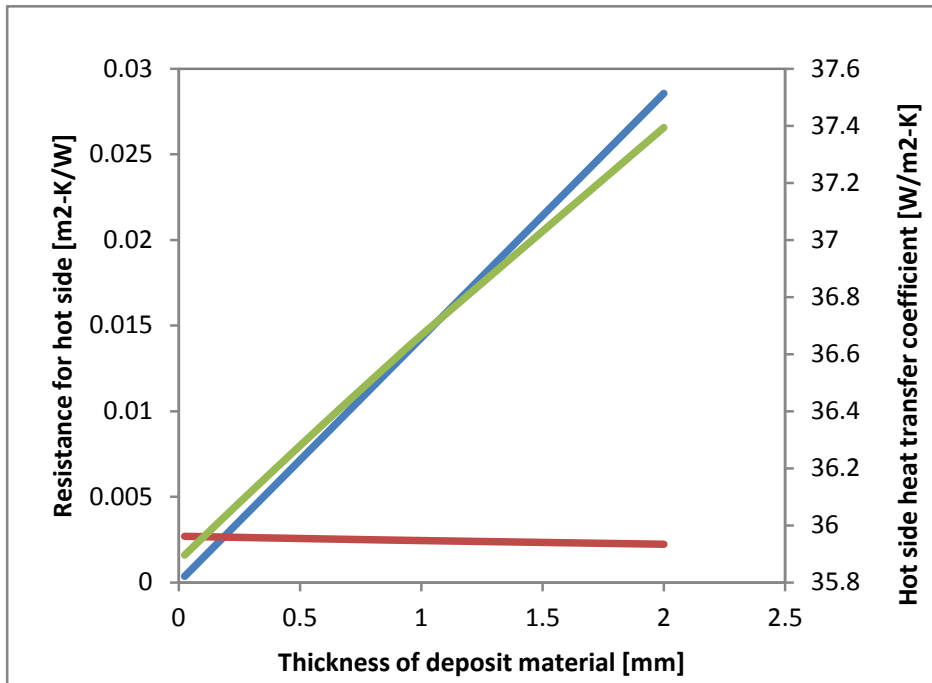

a) $k=0.07 \mathrm{~W} / \mathrm{m}-\mathrm{K}$

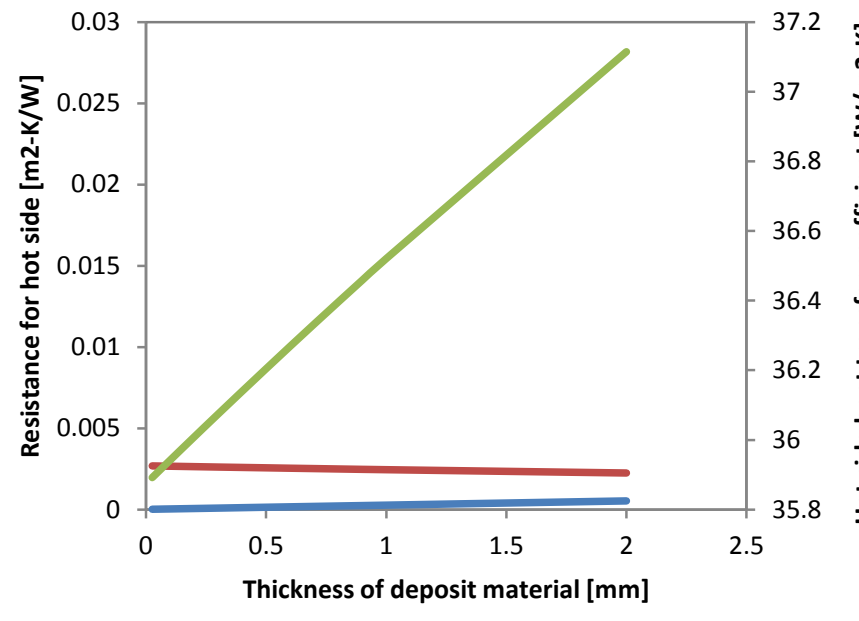

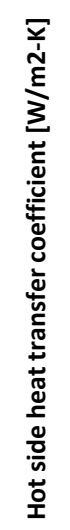

$\longrightarrow$ Rf hot side $\longrightarrow$ Rh hot side $\longrightarrow \mathrm{h}$ hot side

b) $k=3.78 \mathrm{~W} / \mathrm{m}-\mathrm{K}$ 
Figure 7

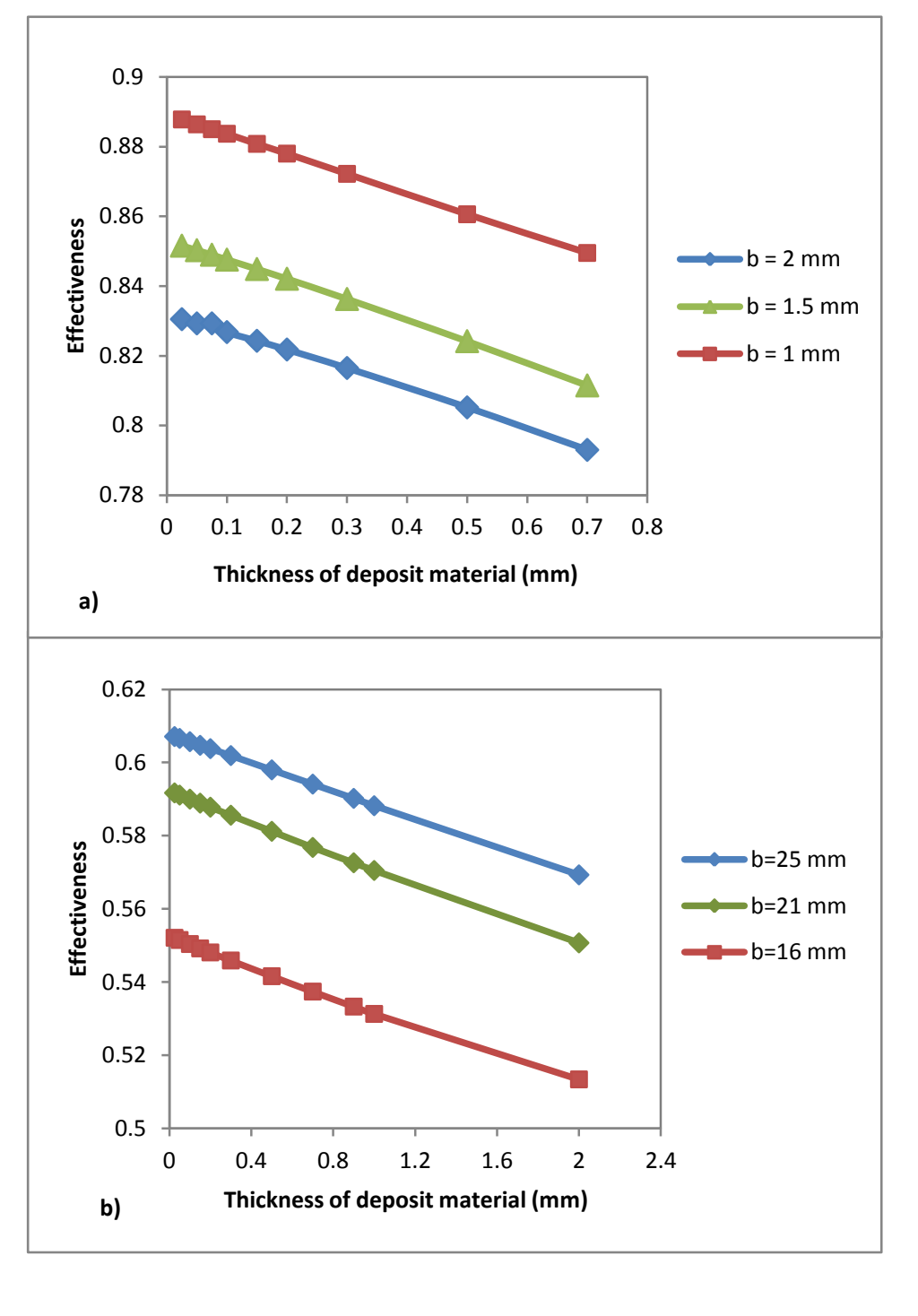

Figure 7.

7
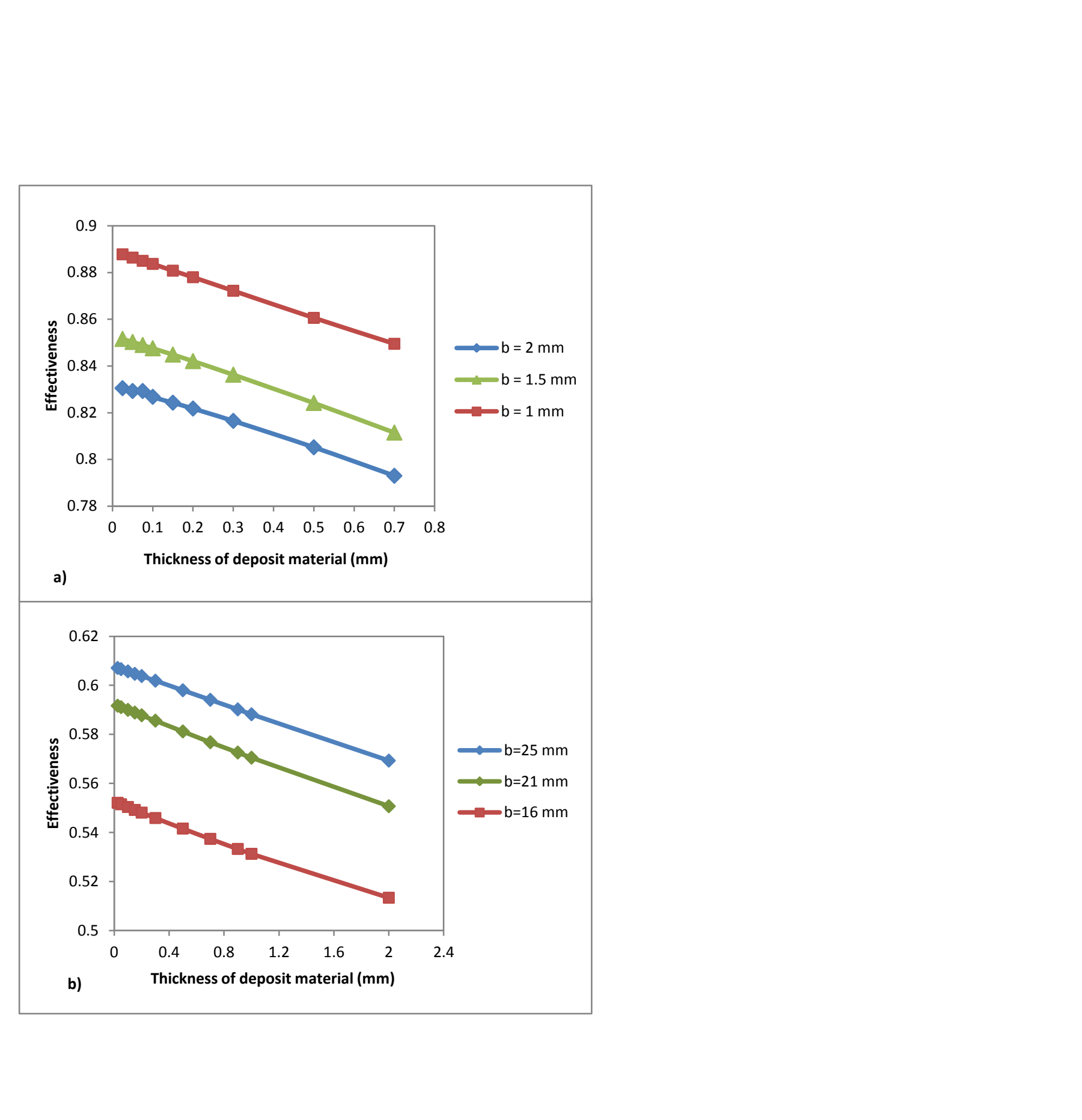
Figure 8

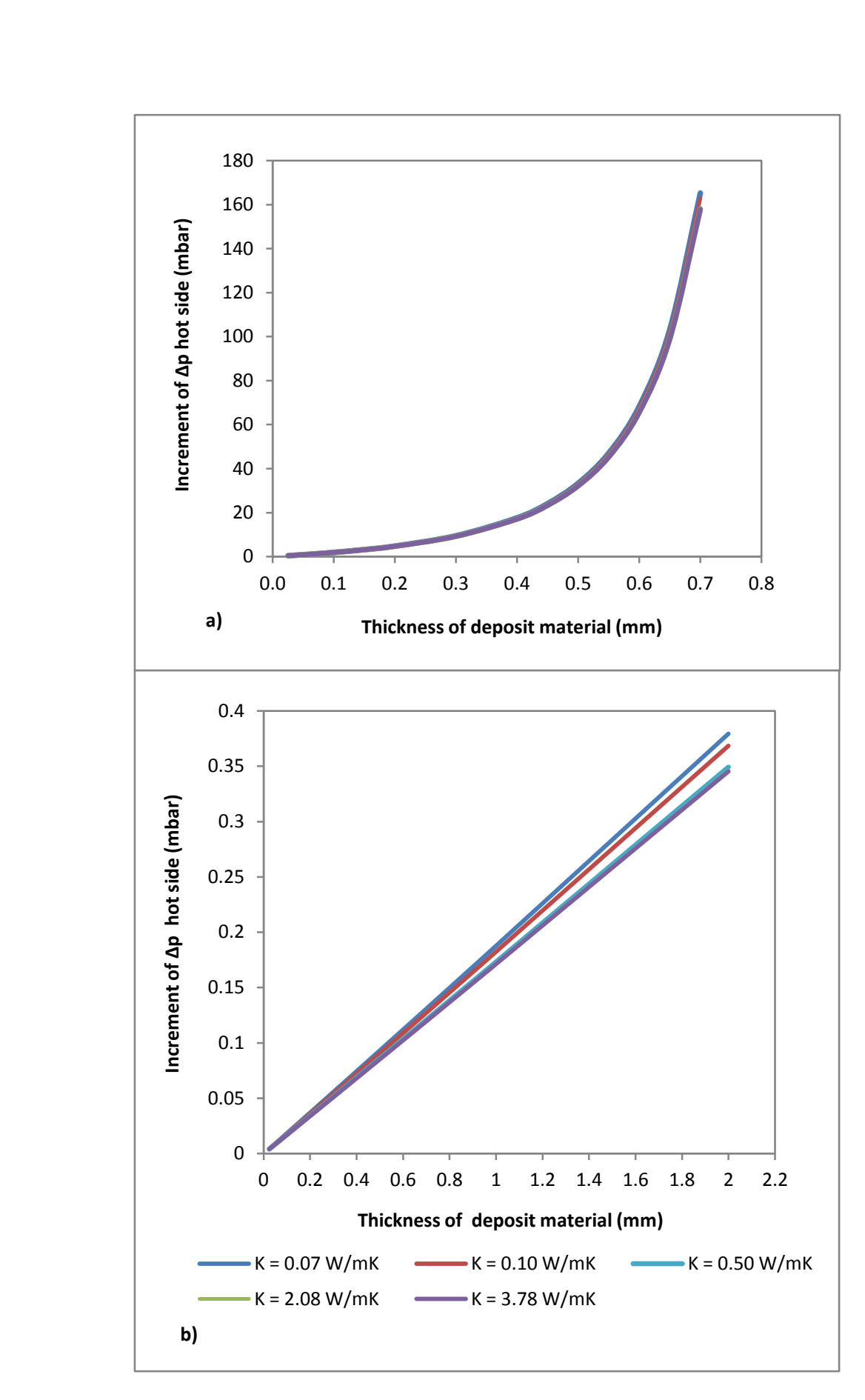

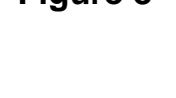

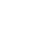
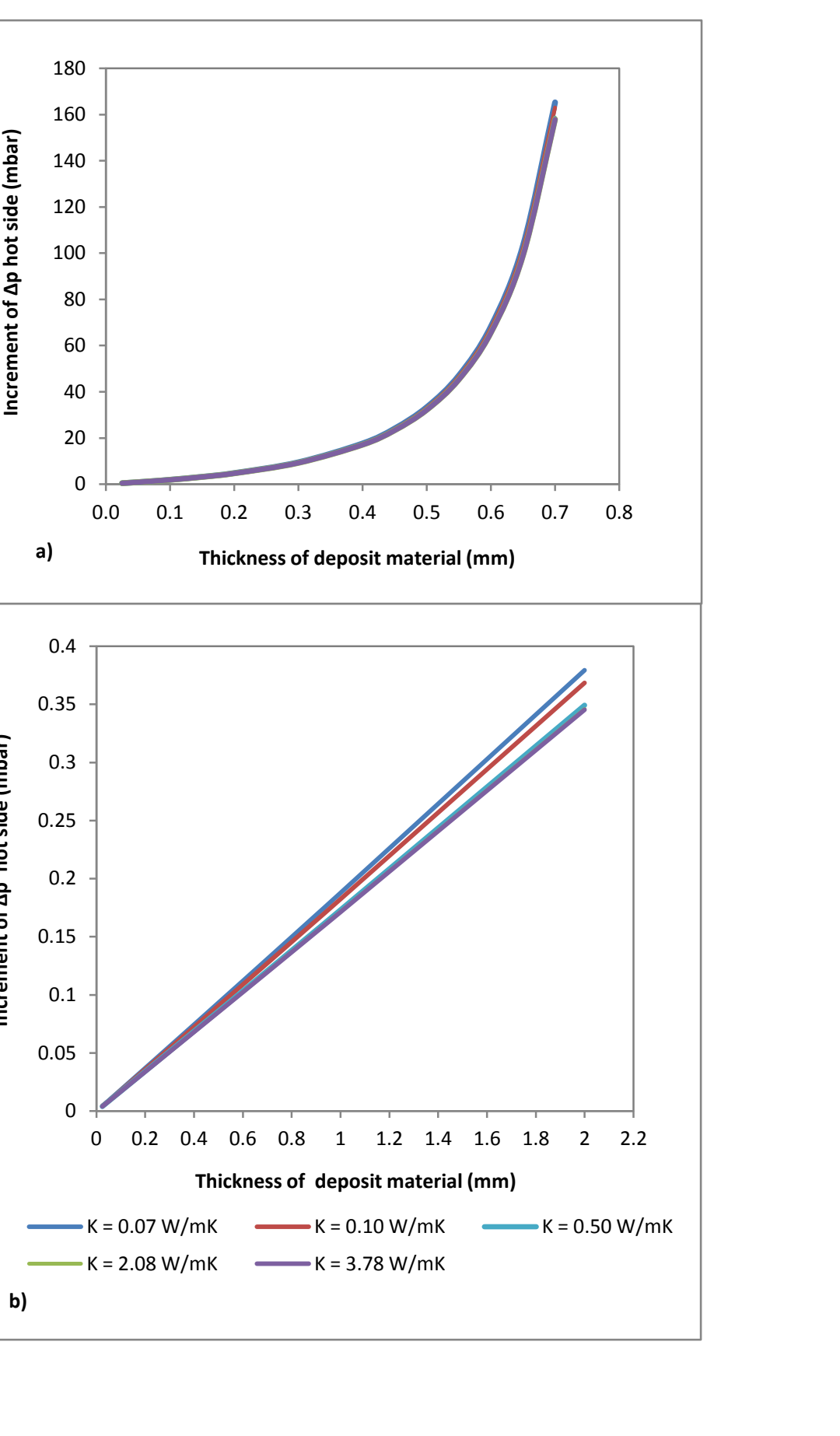
Figure 9

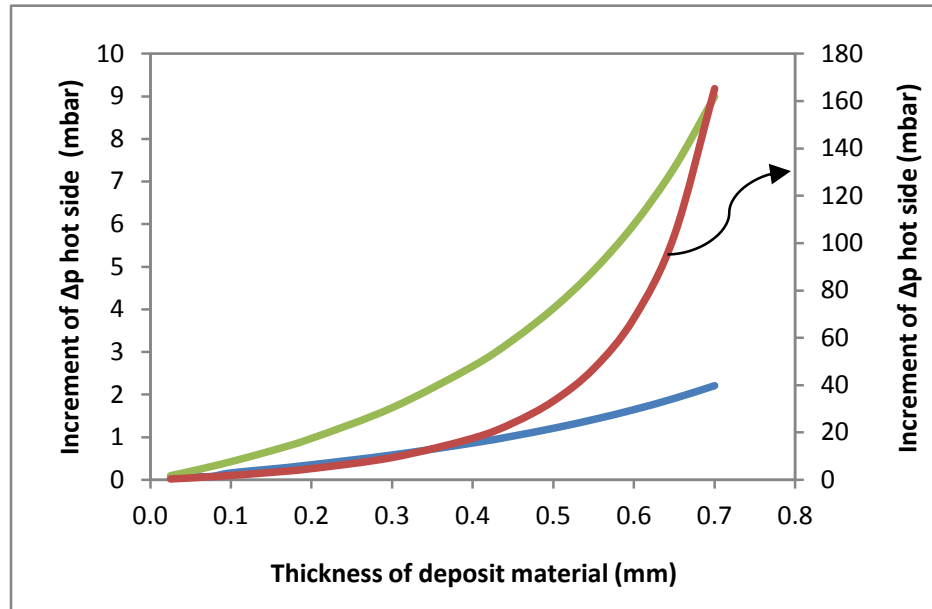

a)
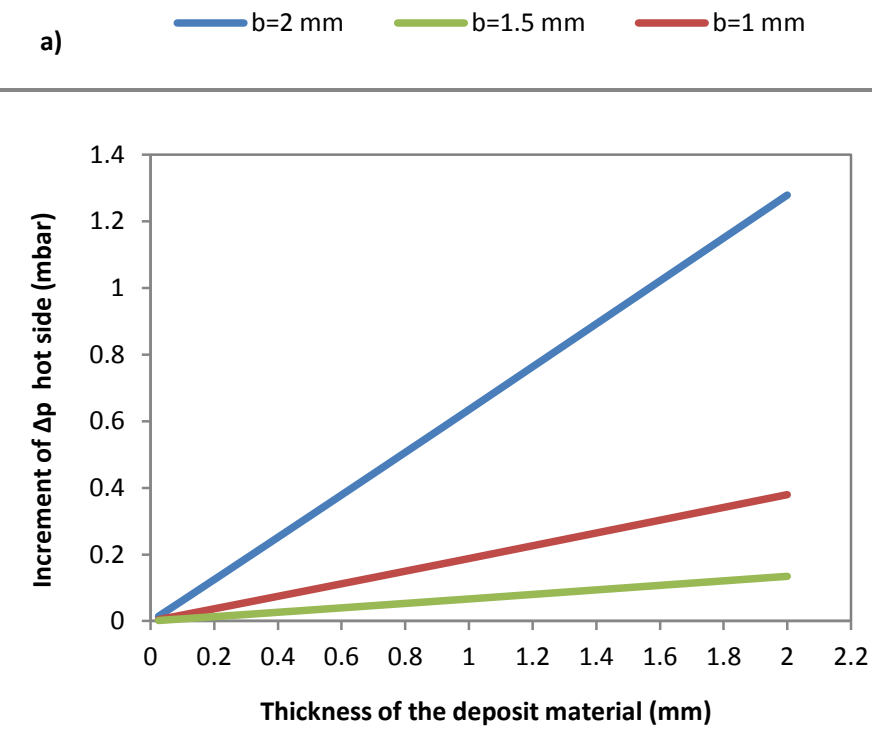

b)

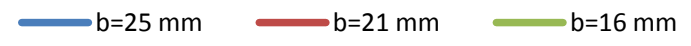




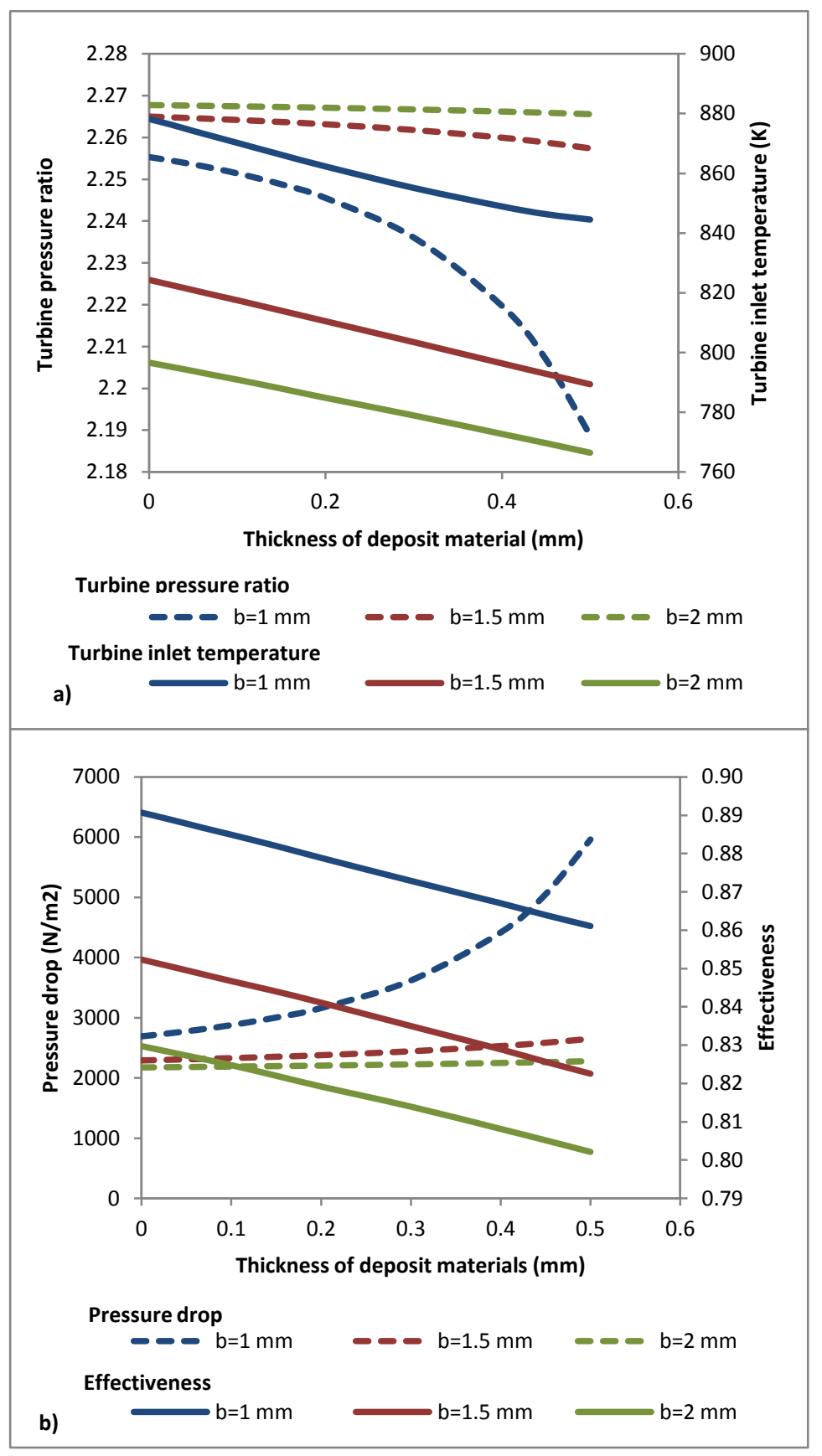

